\title{
Analysis on Impact of Land Use Change on Urban Waterlogging Caused by Floods
}

\author{
Yanan Liu ${ }^{1}$, Maohui Zheng ${ }^{2}$, and Nianqing Zhou ${ }^{1, *}$ \\ ${ }^{1}$ School of Civil Engineering, Tongji University, Shanghai 200092, China; \\ ${ }^{2}$ Shanghai Institute of Disaster Prevention and Relief, Tongji University, Shanghai 200092, China
}

\begin{abstract}
In recent years, ultra-high-intensity rainfall at home and abroad has caused frequent urban waterlogging disasters, posing a severe threat to people's lives, property and city's safety. Based on the satellite image data of Shanghai Waigaoqiao Free Trade Zone in different periods and the Storm Water Management Model (SWMM), this paper establishes a model of heavy rainfall under the underlying surface of a complex city, and analyses topographic features, different land use types, rainfall infiltration intensity and the characteristics of the drainage pipe network. The rainwater accumulation under different rainstorms and urbanization levels is simulated and analysed. The research results show that urban rainstorm accumulation is closely related to land use changes. With the increase of surface impermeability and rainfall intensity, the risk of waterlogging in the study area tends to increase: From 1994 to 2019, the construction area has increased from $2.5096 \mathrm{~km}^{2}$ to $5.8662 \mathrm{~km}^{2}$ in the study area. Compared with 1994 , under the same rainfall conditions, the simulated flooding node and runoff coefficient in 2019 both increased significantly.
\end{abstract}

\section{Introduction}

With the acceleration of global warming and urbanization, extreme weather has occurred frequently. Urban flooding and other disasters have caused severely restrict to the sustainable development of society, economic, the safe operation of cities, and have a huge impact on people's production and life. Coastal cities are low-lying and densely populated, and are extremely vulnerable to flooding ${ }^{[1-3]}$. For example, on September 13, 2013, Shanghai was hit by a heavy rainstorm, which caused many roads flooded, the traffic was almost paralyzed, and many subway lines were also affected.

How to accurately simulate and predict waterlogging disasters is a hot research topic in recent years. Zheng et al ${ }^{44]}$ combined remote sensing data with SCS hydrological model to analyse the impact of land use changes in Shenzhen on surface runoff. Wang et al. ${ }^{[5]}$ used Mike Urban model to simulate the surface runoff process in different rainfall return periods. Quan [6] simulated the depth and degree of rainstorms based on spatial analysis. Since its inception in 1971, the Storm Water Management Model (SWMM) has been widely used in hydrology and water quality simulation. Many scholars [7-10] have built SWMM models to simulate waterlogging with good results. The change of land use type is one of the many factors that affect urban waterlogging, and it is the most important change feature in the process of urbanization ${ }^{[11-13]}$. At present, most waterlogging studies mainly consider surface runoff and underground drainage pipe network confluence data, which lack of consideration of the impact of land use changes on waterlogging. This paper comprehensively considers the surface coverage, surface runoff process and drainage system confluence process, constructs a waterlogging model in Waigaoqiao area based on SWMM software, studies and discusses the impact of land use changes on urban waterlogging disasters.

\section{Data and methods}

\subsection{Study Area}

Shanghai is located at the mouth of the Yangtze River, east of the East China Sea, and south of Hangzhou Bay. It is the centre of China's north and south coasts. Since the "Reform and Opening-up" policy implementation, Shanghai have ushered in opportunities for rapid development, and land use types have undergone tremendous changes. The area of arable land has decreased from $4,040 \mathrm{~km} 2$ in 1994 to $1916.03 \mathrm{~km} 2$ in 2019 , a reduction of $52.57 \%{ }^{[14]}$. The increase in construction land has greatly reduced the precipitation infiltration, and it is easy to form ground runoff. Compared with rapid urbanization, the drainage capacity of the urban drainage system has not kept up with the pace of urban development. Under weather conditions such as heavy rains and typhoons, it is easy to cause surface water and urban floods, which affect people's safety and lives.

The study area is located in the Waigaoqiao Free Trade Zone, Pudong New Area, in Shanghai. The

\footnotetext{
* Nianqing Zhou: nq.zhou@tongji.edu.cn
} 
specific location is between Yanggao North Road, Fute North Road, Haigao Road and Wuzhou Avenue. The total area is $8.25 \mathrm{~km}^{2}$, and it is significantly affected by the subtropical monsoon climate [15]. For research needs, use BIGEMAP to download the satellite image data of the study area in 1994 and 2019, the land use change data of the study area is obtained, as shown in Figure 1.

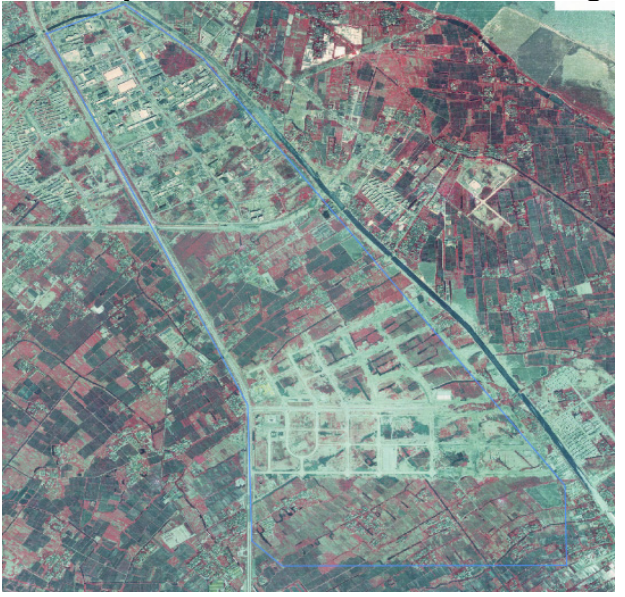

(a) 1994

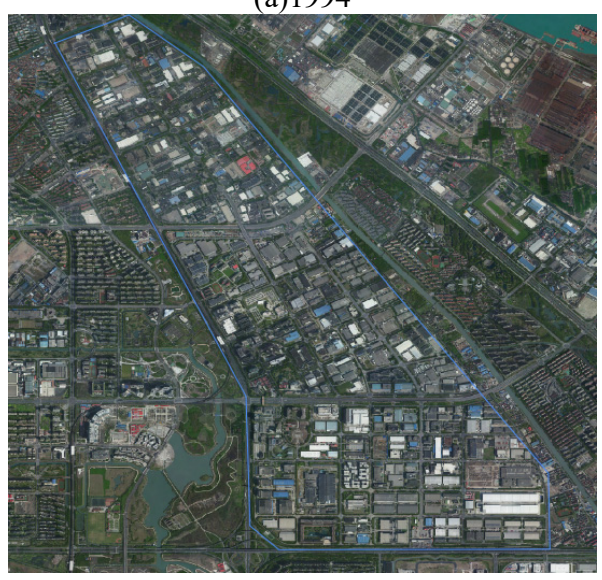

(b) 2019

Fig. 1 Satellite images of Waigaoqiao

\subsection{Methodology}

Input the GIS data of the pipe network, which contain the coordinates and attributes of drainage wells and pipeline start and end points into the SWMM model. A rainfall runoff model in the study area that verify with measured rainfall data was constructed. Analyse the model under different rainfall scenarios and land use types.

\subsubsection{SWMM model generalization}

The Storm Water Management Model (SWMM) is used frequently in current research. It is a dynamic urban storm flood model developed by the U.S. Environmental Protection Agency (EPA) in 1971. It can simulate a single rainfall or long-term water quality. ${ }^{[16]}$.

The construction of SWMM first needs to input topographic data, land use data, etc. into the model. The original pipeline network data is generalized, including the deletion of repeated pipe sections and nodes, the correction of the upstream and downstream relationship of the pipeline. Divide the subcatchment area. According to the pipeline catchment situation and actual topography, the study area is divided into several subcatchments, where the runoff process is calculated separately according to the characteristics of each subcatchment. For the impervious part of the subcatchment, the production flow is equal to the rainfall minus the initial loss caused by evapotranspiration; for the flow production on the permeable area, the amount of depression, infiltration, and initial loss caused by evapotranspiration need to be deducted. Finally, the divided subcatchment is generalized into a non-linear reservoir, and the Manning equation and the continuous equation are solved simultaneously.

When performing numerical simulating calculations, it is necessary to calibrate the main parameters of the model. According to the actual conditions of each subcatchment and the recommended values in the SWMM user's manual, determine the slope, characteristic width, impervious area ratio, pervious surface Manning coefficient and impervious surface Manning coefficient of the subcatchment ${ }^{[17,18]}$. The specific property values are shown in Table 1.

Table 1. main property values of SWMM model

\begin{tabular}{cc}
\hline Parameter & Value \\
\hline Dstore-Perv & $5.08 \mathrm{~mm}$ \\
Dstore-Imperv & $1.27 \mathrm{~mm}$ \\
N-Perv & 0.24 \\
N-Imperv & 0.01 \\
\hline
\end{tabular}

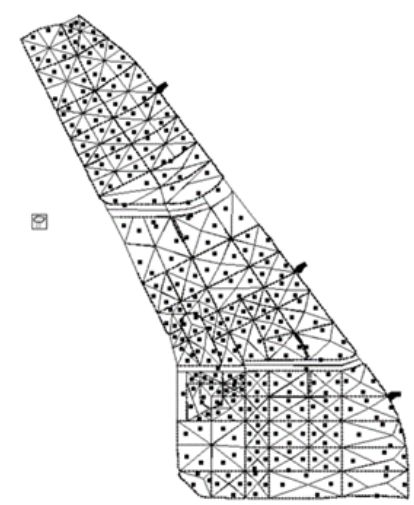

Fig. 2 Generalized diagram of nodes and pipelines in the study area

\subsubsection{Designed rainfall}

The According to the "Standard of Rainstorm Intensity Formula and Design Rainstorm Distribution"[19], Shanghai adopts a unified short-duration storm intensity formula:

$$
i=\frac{1600(1+0.846 \lg P)}{167(t+7)^{0.656}}
$$

In which, $\mathrm{i}$ is rainfall intensity $(\mathrm{mm} / \mathrm{min}) ; \mathrm{P}$ is rainfall return period, year (a); $\mathrm{t}$ is rainfall duration( $\mathrm{min})$;

The research area is the non-central urban area of Shanghai. The duration of the rainstorm is 120 minutes and the peak value of the storm is 0.4 . 


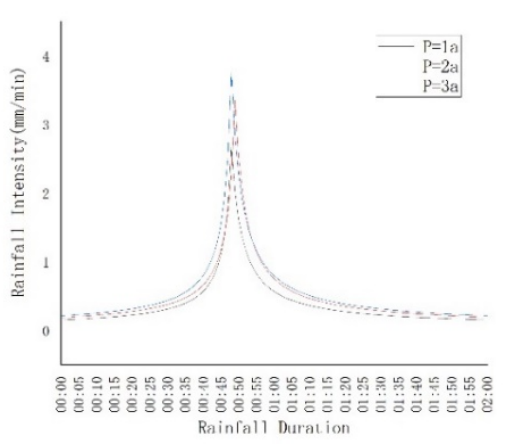

Fig. $32 \mathrm{~h}$ designed rainstorm under different rainfall return period $(\mathrm{P}=1 \mathrm{a}, \mathrm{P}=2 \mathrm{a}, \mathrm{P}=3 \mathrm{a})$

\subsubsection{Model verification}

Rainfall per minute measured by Typhoon "Lekima" transit through Shanghai at the Waigaoqiao Wharf Meteorological Observatory in Pudong was taken as the rainfall process to verify SWMM model. The rainfall time series is shown in the figure below (Fig.4).

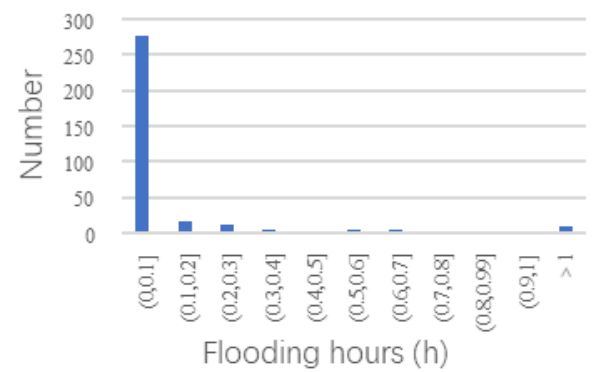

Fig. 4 Distribution of waterlogging time and number of flooding nodes under Typhoon "Lekima

\section{Results and analysis}

\subsection{Land use changes in the study area}

According to satellite image data, the study area has undergone tremendous changes in the past 25 years. Land use types are mainly divided into three categories: agricultural land, construction land and unused land. This article mainly compares the changes in the area of buildings and roads in the study area, which can be seen as the construction land.

Using BIGEMAP software, statistics of buildings and roads on satellite images in 1994 and 2019 were obtained. In the 1990s, the land types in the Waigaoqiao area were mainly agricultural land. With the rapid development of Pudong New Area, the construction land continues to increase, and land use types have changed greatly. The construction land area of the study area has increased from $2.5096 \mathrm{~km}^{2}$ in 1994 to $5.8662 \mathrm{~km}^{2}$ in 2019 , with a growth rate of $133.75 \%$.

\subsection{Analysis of simulation results}

By integrating remote sensing data and SWMM model, the percentage of impervious land was put into the model, the water accumulation under different design rainfall return periods $(\mathrm{P}=1 \mathrm{a},=2 \mathrm{a}, \mathrm{P}=3 \mathrm{a})$ were compared. The results are shown in the table 2 .

Table 2. Comparison of waterlogging under different return

\begin{tabular}{|c|c|c|c|c|c|}
\hline & $\begin{array}{l}\text { Rain- } \\
\text { fall } \\
\text { return } \\
\text { period }\end{array}$ & $\begin{array}{c}\text { The number } \\
\text { of flooding } \\
\text { nodes with a } \\
\text { water } \\
\text { accumulation } \\
\geq 0.1 \mathrm{~m}^{3}\end{array}$ & $\begin{array}{l}\text { Average } \\
\text { flooding } \\
\text { hour(h) }\end{array}$ & $\begin{array}{l}\text { Average } \\
\text { flooding } \\
\text { volume } \\
\left(\mathrm{m}^{3}\right)\end{array}$ & $\begin{array}{l}\text { Average } \\
\text { runoff } \\
\text { coefficient }\end{array}$ \\
\hline \multirow{3}{*}{1994} & $\mathrm{P}=1 \mathrm{a}$ & 55 & 0.06 & 0.03 & 0.34 \\
\hline & $\mathrm{P}=2 \mathrm{a}$ & 91 & 0.08 & 0.05 & 0.36 \\
\hline & $\mathrm{P}=3 \mathrm{a}$ & 117 & 0.1 & 0.07 & 0.38 \\
\hline \multirow{3}{*}{2019} & $\mathrm{P}=1 \mathrm{a}$ & 188 & 0.15 & 0.13 & 0.74 \\
\hline & $\mathrm{P}=2 \mathrm{a}$ & 231 & 0.2 & 0.2 & 0.75 \\
\hline & $\mathrm{P}=3 \mathrm{a}$ & 253 & 0.23 & 0.25 & 0.76 \\
\hline
\end{tabular}

Table 2 shows that as the design rainfall return periods increases, the number of flooding nodes and average flooding volume are increasing due to the decrease of pervious surface area. In the past 25 years, the types of land use in the Waigaoqiao area and the results of the model simulation of waterlogging have changed greatly, the average runoff coefficient of the study area has increased significantly. Under the conditions of design rainfall return periods of $1 \mathrm{a}, 2 \mathrm{a}$, and $3 \mathrm{a}$, the runoff coefficient nearly doubled. A larger average runoff coefficient means that the amount of surface infiltration decreases and the burden on the drainage network increases.

It can be approximately considered that the proportion of flooding nodes to the total number of nodes is the same as the actual waterlogging situation. Under 1994's land use type, the number of simulated waterlogging points was small, and the flooding volume at the node exceeded the water-passing capacity, but the waterlogging time was short and the waterlogging situation was slight. However, under 2019's land use type, the number of flooding nodes increased; In 1994, the waterlogging situation in the study area is relatively flat, while under the surface cover in 2019, the waterlogging situation in the study area is relatively serious.

\subsection{The simulation of pipeline surcharging analysis}

According to the simulation results of the SWMM model, the results of pipeline surcharging duration under different land use types and different rainfall return periods are shown in Table 4. The number of surcharging pipelines is increasing with the increase in the rainfall return period. Under the same rainfall scenario, the larger the impermeable area of the surface, the greater the number of surcharging pipelines. In 25 years, the number of surcharging pipelines under three simulated rainfall conditions increased by $38.13 \%$, $10.63 \%$ and $8.4 \%$ respectively.

Table 3. Statistic of Conduit Surcharging Hours in research

\begin{tabular}{ccc}
\multicolumn{3}{c}{ area } \\
\hline Pipeline & 1994 & 2019 \\
\hline
\end{tabular}




\begin{tabular}{ccccccc}
\cline { 1 - 1 } $\begin{array}{c}\text { surcharging } \\
\text { duration }(\mathrm{h})\end{array}$ & $\begin{array}{c}\mathrm{P}=1 \\
\mathrm{a}\end{array}$ & $\begin{array}{c}\mathrm{P}=2 \\
\mathrm{a}\end{array}$ & $\begin{array}{c}\mathrm{P}=3 \\
\mathrm{a}\end{array}$ & $\begin{array}{c}\mathrm{P}=1 \\
\mathrm{a}\end{array}$ & $\begin{array}{c}\mathrm{P}=2 \\
\mathrm{a}\end{array}$ & $\begin{array}{c}\mathrm{P}=3 \\
\mathrm{a}\end{array}$ \\
\hline$(0.1,0.5]$ & 70 & 106 & 121 & 103 & 97 & 92 \\
\hline$(0.5,1]$ & 40 & 50 & 38 & 50 & 59 & 69 \\
\hline$(1,2]$ & 25 & 18 & 21 & 33 & 34 & 32 \\
\hline$>2$ & 25 & 33 & 34 & 35 & 39 & 39 \\
\hline Total & 160 & 207 & 214 & 221 & 229 & 232
\end{tabular}

In order to evaluate the pipeline surcharging situation in the test area intuitively, when the rainfall return period is $1 \mathrm{a}$, the surcharging situation of the drainage piping system when the rainfall intensity is the highest is shown in Figure 5. The red color represents the surcharging pipe section. When the rainfall time is 1:00, the rainfall intensity is the highest, and the number of surcharging pipelines is the largest; after the rain peak, the flow rate and the number of surcharging pipelines in the drainage system gradually decrease; when the rainfall ends (2:00), only a few pipelines are surcharging; two hours after the rainfall end (4:00), there is no surcharging pipeline, all pipelines resume normal operation.

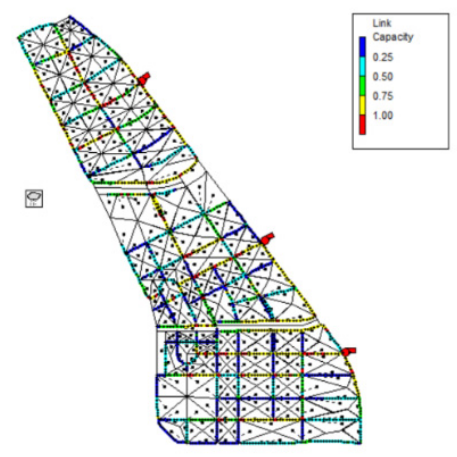

(a) $\mathrm{P}=1 \mathrm{a}$, 1994's land cover

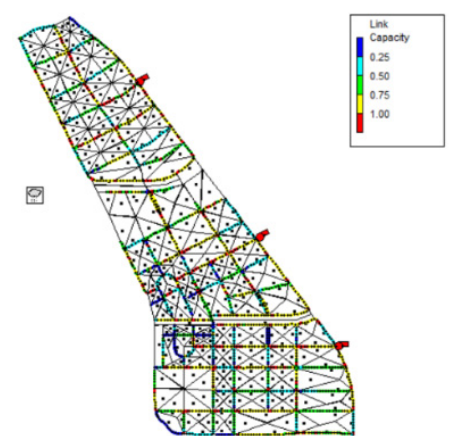

(b) $\mathrm{P}=1 \mathrm{a}, 2019$ 's land cover

Fig.5 Conduit Surcharging Status at 1:00

\section{Conclusion}

In this paper, the SWMM model of drainage pipe network is established according to the change of land use type. With reference to the satellite image data of Shanghai Waigaoqiao area in 1994 and 2019, three short-duration rainstorms were designed in this model. The water accumulation under different land use types and different designed rainfall conditions are compared. The following conclusions can be drawn: (1) The construction land area of the test area has increased from $2.5096 \mathrm{~km} 2$ to $5.8662 \mathrm{~km} 2$. In the past 25 years, changes in land use types have exacerbated the risk of waterlogging; In 2019, the simulated waterlogging nodes increased. The surface area of infiltration has decreased, reducing the infiltration of rainwater, which is easy to form surface runoff during heavy rains. However, the existing drainage system cannot discharge in time, which can easily cause waterlogging disasters. (2) The designed rainfall return periods are $1 \mathrm{a}, 2 \mathrm{a}$ and $3 \mathrm{a}$. Under the conditions of 1994's land use, the runoff coefficients are $0.34,0.36,0.38$, the pipelines surcharging duration exceeds $0.1 \mathrm{~h}$ 's number is 160, 207 and 214; Under the 2019's land use condition, the runoff coefficients are $0.74,0.75$ and 0.76 ; the pipelines surcharging duration exceeds 0.1 h's number is 221,229 and 232 . In the future, coastal cities need to consider the impact of urbanization in multiple directions and formulate reasonable drainage network planning to reduce the occurrence of waterlogging.

\section{Acknowledgments}

This article is one of the phased achievements of the National Key Research and Development Program (2016YFC0802400, 2017YFC0803300)

\section{References}

1. Wang Wenwen, Zhao Zhijie, Qin Huapeng. Hydrological effect assessment of low impact development for urbanized area based on SWMM[J] Acta Scientiarum Naturalium Universitatis Pekinen, 2012, 48(2): 303-309.

2. Yin Zhan'e, $\mathrm{Xu}$ Shiyuan, Yin Jie, et al. Scenario simulation and risk assessment of urban rainstorm and waterlogging disaster based on small-scale [J]. Acta Geographica Sinica, 2010, 65(005): 553-562.

3. Zhang Wei, Li Simin, Shi Zhennan. Formation causes and coping strategies of urban rainstorm waterlogging in China $[\mathrm{J}]$. Journal of Natural Disasters, 2012(05): 180-184.

4. Zheng J, Yuan Y, Feng WL, et al. Model research on impact of land-use change on surface runoff depth: a case studyon Shenzhen Region [J]. Journal of Natural Disasters, 2005, 14(06): 077-82.

5. Dong W, Lian Y, Zhang Y. [Environmental Earth Sciences] Sustainable Development of Water Resources and Hydraulic Engineering in China \| Flow Chocking Characteristics of Leak-Floor Flip Buckets[J]. 2019, 10.1007/978-3- 319-61630-8 (Chapter 2): 7-18.

6. Quan RS. Rainstorm waterlogging risk assessment in central urban area of Shanghai based on multiple 
scenario simulation[J]. Natural Hazards, 2014, 73(6):1569-1585.

7. Cong Xiangyu, Ni Guangheng, Hui Shibo, et al. Simulative analysis on storm flood in typical urban regiOH of Beijing based Oil SWM [J]. Water Resources and Hydropower Technology, 2006(04): 64-67.

8. Gao B, Zhuang B Y. Study on Rain Water Drainage System Plan Based on SWMM[J]. Advanced Materials Research, 2013, 790:125-128.

9. Xue Fengchang, Gao Xiaodong, Qian Jin, et al. Numerical simulation of urban waterlogging based on GIS[J]. Geomatics \& Spatial Information Technology, 2012(12): 23-25.

10. Jia Yanmei, Feng Shucang. Depth simulation of rainstorm in Cangzhou city based on SWMM model[J]. Journal of Hebei Engineering and Technology College, 2016(2): 15-20.

11. Rogger M, Viglione A, Derx J, et al. Quantifying effects of catchments storage thresholds on step changes in the flood frequency curve[J]. Water resources research, 2013, 49(10): 6946-6958.

12. Lúbomír Solín, Ján Feranec, Jozef Nováek. Land cover changes in small catchments in Slovakia during 1990-2006 and their effects on frequency of flood events[J]. Natural Hazards, 2011, 56(1): 195214.

13. Wang $\mathrm{Xi}$, Yang Xiaoliu, $\mathrm{Xu}$ Chaowei, et al. Landuse-based analysis of waterlogging traffic risk[J]. Journal of Natural Disasters, 2018, 27(05): 199-206.

14. Shi Lijiang, Wang Shengyun, Yao Xiaojun, et al. Spatial-temporal changes and driving forces of land use in Shanghai from 1994 to 2006 [J]. Resources and Environment in the Yangtze River Basin, 2012, 21(12): 1468.

15. Shanghai Municipal Statistics Bureau, Survey Office of the National Bureau of Statistics in Shanghai. ShangHai Statistical Yearbook 2018[M]. China Statistics Press, 2019

16. Dong Xin, Chen Jining, Zhao Dongquan. Application of SWMM model in urban drainage system planning[J]. Water Supply and Wastewater, 2006(05): 106-109.

17. Tao Tao, Yan Hexiang, Li Shuping, et al. Discussion on key issues of urban rainwater management model (1)-Confluence model [J]. Water Supply and Wastewater, 2017, 43(03): 36-40.

18. Tao Tao, Yan Hexiang, Li Shuping, et al. Discussion on key issues in urban rainwater management model (2)-infiltration model[J]. Water Supply and Drainage, 2017, 43(09): 115-119.

19. Ministry of Housing and Urban-Rural Development of the People's Republic of China. GB50014-2006 Code for design of outdoor wastewater engineering (2014 Edition) [M]. China Planning Press, 2014. 